\title{
Comparative Analysis of Eight Undergraduate Universities Based on InCites Database
}

\author{
Chunxia Guo \\ Library, Binzhou University, Binzhou, China \\ Email: 87535293@qq.com
}

How to cite this paper: Guo, C.X. (2019) Comparative Analysis of Eight Undergraduate Universities Based on InCites Database. Open Journal of Social Sciences, 7, 282-293.

https://doi.org/10.4236/jss.2019.74022

Received: March 22, 2019

Accepted: April 20, 2019

Published: April 23, 2019

Copyright (c) 2019 by author(s) and Scientific Research Publishing Inc. This work is licensed under the Creative Commons Attribution International License (CC BY 4.0).

http://creativecommons.org/licenses/by/4.0/

(c) (i) Open Access

\begin{abstract}
This paper selects the papers collected by Web of Science from 8 local universities in Shandong Province from 2008 to 2018 in the InCites database as a research sample for chemistry, mathematics, engineering, biology and biochemistry, environment and ecology, physics, computer science, and analyzes the amount of documents and the frequency of citations. At the same time, the secondary disciplines with more than 15 papers published in 7 university departments also carried out statistical analysis on the number of publications, citation frequency, and frequency. Using these 7 disciplines, the eight universities will be compared horizontally, and the scientific research gaps between different universities will be located to reveal the research status of the undergraduate universities in Shandong Province of China.
\end{abstract}

\section{Keywords}

Data Analysis, InCites Database, General University, Subject Analysis, Cites, WOS Subject

\section{Introduction}

On September 21, 2017, the Ministry of Education, the Ministry of Finance, and the National Development and Reform Commission jointly announced the list of universities and construction disciplines for world-class universities and first-class disciplines. The construction of first-class universities relies on the construction of first-class disciplines. Therefore, improving the scientific research level of universities is the foundation and premise of building a world-class university [1]. Academic papers are an important embodiment of evaluating the scientific research achievements and scientific research innovations of a university [2]. The number of papers and the number of citations are one of the important indicators to measure the level of research in schools, research institutions and 
even the country. Web of Science is an internationally recognized representative tool that reflects the research level of basic subjects.

InCites is an authoritative scientific evaluation and analysis tool based on Web of Science data, not limited to document types [3]. The number of papers in the InCites database comes from the seven database indexes of SCI-E, SSCI, A \& HCI, CPCI-S, CPCI-SS \& H, BKCI-S, and BKCI-SSH [4]. InCites can locate key disciplines, dominant disciplines, and development potential disciplines, optimize discipline layout, track and evaluate the research performance of institutions, and conduct benchmarking analysis with peer organizations.

\section{Data Source}

In order to analyze the research gaps and scientific research capabilities among ordinary undergraduate universities, this paper selects 8 universities in Binzhou University, Linyi University, Dezhou University, Taishan University, Jining University, Weifang University, Heze University and Zaozhuang University as research samples. These 8 universities are all ordinary undergraduate universities in Shandong Province, and none of them have entered the ESI database. These 8 universities are the most authoritative comprehensive universities in the city, and they are all located in the second-tier cities of Shandong Province. The GDP and population of the cities are basically the same. Since these 8 universities are all local universities, the majors and advantageous disciplines offered by universities are basically the same.

Using the Incics database, the author compares the papers included in the Web of Science from 2008 to 2018 from seven disciplines: chemistry, mathematics, engineering, biology and biochemistry, environment and ecology, physics, and computer science. To locate the gaps in scientific research between different disciplines between universities, and to clarify the gap between ordinary undergraduate colleges and world-class universities and first-class disciplines, with a view to helping scientific researchers in ordinary universities understand and master the development of disciplines, research frontiers and hot issues. Improve the level of scientific research. The data in this article is directly ranked from the InCites database. The rankings of the eight universities are ranked according to the total citation frequency of each subject.

The data retrieval date is December 20, 2018, December 23, 2018. Since the update of the InCites database is delayed by 2 months, the actual time span of all data is the time span of 2008-2018.10.31. This article selects these seven disciplines because these eight disciplines represent the main research directions of engineering in eight general universities, and the strength of each university's research team is not much different.

\section{Comparative Analysis of WOS Papers in 8 Universities in Shandong Province}

\subsection{Chemistry Subject Analysis}

The core of Web of science divides chemistry into seven secondary disciplines: 
analytical chemistry, applied chemistry, inorganic and atomic chemistry, pharmaceutical chemistry, organic chemistry, physical chemistry, and chemistry related to other disciplines. According to the total number of papers, among the 8 universities, 431 papers from Linyi University ranked first in the number of papers; Dezhou University published 336 papers, ranking second. The least amount of papers was Zaozhuang University, and the number of papers was 107. From the aspect of total citation frequency, the highest is Linyi University, 3798 times. Secondly, Taishan University was cited as 2949 times. The highest frequency of the articles was Taishan University, which was 9.02 times/paper. From the perspective of disciplines, Linyi University's analytical chemistry, physical chemistry, and chemistry related to other disciplines are more than the other seven universities. In terms of inorganic and atomic chemistry, Taishan University has published the most papers.

Among the seven secondary disciplines, Binzhou University, Heze University, and Weifang University have only three research directions, and there are more than 15 research directions. Zaozhuang University has more than 15 subjects in 2 disciplines. It can be seen that in the chemistry discipline, Linyi University has more than the other seven universities regardless of the number and quality of documents issued. See Table 1 for details.

\subsection{Mathematics Subject Analysis}

The core set of $\mathrm{Web}$ of science divides mathematics into four sub-disciplines: interdisciplinary applications in mathematics and computational biology, mathematics, applied mathematics, and mathematics. In terms of the number of papers, Linyi University issued a total of 574 articles, of which mathematics and applied mathematics were the largest in eight universities. It can be seen that Linyi University has certain advantages in these two research directions compared to the other seven universities. Binzhou University published a total of 172 mathematics papers, of which the most published research direction is applied mathematics, a total of 93 , accounting for $54 \%$ of the total number of texts issued by mathematics. The total number of citations was 885 , ranking $2^{\text {nd }}$ among 8 universities. The average number of citations is 5.15 times/paper, which is the highest number of citations in the eight universities. The least amount of papers is Heze University, and there are only 48 papers in WOS. In the second-level discipline of WOS, there are no more than 15 universities in mathematics and computational biology research. It can be seen that the research of mathematics and computational biology in these eight universities is relatively weak. See Table 2 for details.

\subsection{Engineering Discipline Analysis}

The core set of Web of science divides mathematics into 11 secondary disciplines such as electrical and electronic engineering, chemical engineering industrial engineering, and manufacturing engineering. In terms of the number of papers, 
among the 8 universities, Weifang University has 641 articles, and the number of articles is the first. Linyi University issued 611 articles, ranking second. The least amount of papers is Heze University, and the number of papers is 81 . From the perspective of secondary disciplines, Linyi University has the largest number of publications in electrical and electronic engineering; Weifang University's papers in chemical engineering, environmental engineering, and mechanical engineering are higher than other seven universities. The total number of citations of

Table 1. Comparative analysis of chemistry disciplines in 8 universities.

\begin{tabular}{|c|c|c|c|c|c|c|c|}
\hline Rank & Institutions & WOS Documents & Total Cites & Cites/Paper & WOS SUBJECT & papers $\geq 15$ & Cites \\
\hline \multirow[t]{4}{*}{1} & Linyi University & 431 & 3798 & 8.81 & Chemistry, Analytical & 102 & 1344 \\
\hline & & & & & Chemistry, Inorganic \& Nuclear & 28 & 67 \\
\hline & & & & & Chemistry, Multidisciplinary & 145 & 1287 \\
\hline & & & & & Chemistry, Physical & 115 & 759 \\
\hline \multirow[t]{6}{*}{2} & Taishan University & 327 & 2949 & 9.02 & Chemistry, Analytical & 21 & 249 \\
\hline & & & & & Chemistry, Applied & 22 & 265 \\
\hline & & & & & Chemistry, Inorganic \& Nuclear & 96 & 782 \\
\hline & & & & & Chemistry, Multidisciplinary & 86 & 681 \\
\hline & & & & & Chemistry, Organic & 23 & 208 \\
\hline & & & & & Chemistry, Physical & 77 & 731 \\
\hline \multirow[t]{4}{*}{3} & Dezhou University & 336 & 2682 & 7.98 & Chemistry, Analytical & 26 & 263 \\
\hline & & & & & Chemistry, Inorganic \& Nuclear & 85 & 580 \\
\hline & & & & & Chemistry, Multidisciplinary & 122 & 804 \\
\hline & & & & & Chemistry, Physical & 75 & 582 \\
\hline \multirow[t]{4}{*}{4} & Jining University & 315 & 2677 & 8.5 & Chemistry, Inorganic \& Nuclear & 83 & 487 \\
\hline & & & & & Chemistry, Multidisciplinary & 90 & 994 \\
\hline & & & & & Chemistry, Organic & 35 & 152 \\
\hline & & & & & Chemistry, Physical & 87 & 871 \\
\hline \multirow[t]{3}{*}{5} & Binzhou University & 161 & 1080 & 6.71 & Chemistry, Inorganic \& Nuclear & 25 & 107 \\
\hline & & & & & Chemistry, Multidisciplinary & 38 & 224 \\
\hline & & & & & Chemistry, Physical & 68 & 477 \\
\hline \multirow[t]{3}{*}{6} & Heze University & 108 & 691 & 6.4 & Chemistry, Multidisciplinary & 25 & 69 \\
\hline & & & & & Chemistry, Physical & 29 & 122 \\
\hline & & & & & Chemistry, Inorganic \& Nuclear & 33 & 131 \\
\hline \multirow[t]{3}{*}{7} & Weifang University & 159 & 689 & 4.33 & Chemistry, Multidisciplinary & 85 & 177 \\
\hline & & & & & Chemistry, Physical & 21 & 176 \\
\hline & & & & & Chemistry, Multidisciplinary & 47 & 217 \\
\hline \multirow[t]{2}{*}{8} & Zaozhuang University & 107 & 587 & 5.49 & Chemistry, Multidisciplinary & 47 & 217 \\
\hline & & & & & Chemistry, Physical & 37 & 254 \\
\hline
\end{tabular}


Table 2. Comparative analysis of mathematics subjects in 8 universities.

\begin{tabular}{|c|c|c|c|c|c|c|c|}
\hline Rank & Institutions & WOS Documents & Total Cites & Cites/Paper & WOS SUBJECT & papers $\geq 15$ & Cites \\
\hline \multirow[t]{3}{*}{1} & Linyi University & 574 & 1686 & 2.94 & Mathematics & 237 & 553 \\
\hline & & & & & Mathematics, Applied & 274 & 872 \\
\hline & & & & & Mathematics, Interdisciplinary Applications & 55 & 261 \\
\hline \multirow[t]{3}{*}{2} & Binzhou University & 172 & 885 & 5.15 & Mathematics & 53 & 167 \\
\hline & & & & & Mathematics, Applied & 93 & 595 \\
\hline & & & & & Mathematics, Interdisciplinary Applications & 25 & 104 \\
\hline \multirow[t]{2}{*}{3} & Weifang University & 196 & 516 & 2.63 & Mathematics & 73 & 183 \\
\hline & & & & & Mathematics, Applied & 108 & 234 \\
\hline \multirow[t]{3}{*}{4} & Dezhou University & 99 & 509 & 5.14 & Mathematics & 23 & 51 \\
\hline & & & & & Mathematics, Applied & 46 & 225 \\
\hline & & & & & Mathematics, Interdisciplinary Applications & 19 & 130 \\
\hline \multirow[t]{3}{*}{5} & Taishan University & 93 & 428 & 4.6 & Mathematics & 16 & 69 \\
\hline & & & & & Mathematics, Applied & 54 & 289 \\
\hline & & & & & Mathematics, Interdisciplinary Applications & 20 & 70 \\
\hline \multirow[t]{3}{*}{6} & Zaozhuang & 116 & 280 & 2.41 & Mathematics & 32 & 98 \\
\hline & University & & & & Mathematics, Applied & 49 & 132 \\
\hline & & & & & Mathematics, Interdisciplinary Applications & 28 & 39 \\
\hline \multirow[t]{2}{*}{7} & Jining University & 54 & 122 & 2.26 & Mathematics & 17 & 33 \\
\hline & & & & & Mathematics, Applied & 22 & 62 \\
\hline \multirow[t]{2}{*}{8} & Heze University & 48 & 83 & 1.73 & Mathematics & 16 & 11 \\
\hline & & & & & Mathematics, Applied & 26 & 66 \\
\hline
\end{tabular}

Binzhou University Engineering was 1229 times, and the frequency of citations was 5.06 times/paper, which was higher than that of other 7 universities. However, the number of papers sent in all directions in the engineering discipline is relatively average, and there is no dominant research direction. The number of publications in the biomedical engineering, geological engineering and petroleum engineering of the eight universities is less than 15 articles. It can be seen that the undergraduate colleges have less research on these two secondary disciplines of engineering. Especially for aerospace engineering, only Binzhou University published three related papers, and none of the other seven universities published relevant academic papers.

Based on the various data, the engineering discipline of Heze University has the least amount of publications and the least influence. Although Binzhou University has the highest number of citations, it has a small number of publications and needs to increase the number of publications. See Table 3.

\subsection{Biological and Biochemical Discipline Analysis}

The core of Web of science is a two-level discipline of biochemistry research methods 
Table 3. Comparative analysis of engineering in 8 universities.

\begin{tabular}{|c|c|c|c|c|c|c|c|}
\hline Rank & Institutions & WOS Documents & Total Cites & Cites/Paper & WOS SUBJECT & papers $\geq 15$ & Cites \\
\hline \multirow[t]{6}{*}{1} & Binzhou University & 243 & 1229 & 5.06 & Engineering, Electrical \& Electronic & 58 & 145 \\
\hline & & & & & Engineering, Chemical & 43 & 252 \\
\hline & & & & & Engineering, Environmental & 34 & 393 \\
\hline & & & & & Engineering, Mechanical & 31 & 159 \\
\hline & & & & & Engineering, Multidisciplinary & 26 & 51 \\
\hline & & & & & Engineering, Manufacturing & 18 & 34 \\
\hline \multirow[t]{5}{*}{2} & Taishan University & 191 & 803 & 4.2 & Engineering, Electrical \& Electronic & 80 & 259 \\
\hline & & & & & Engineering, Chemical & 20 & 242 \\
\hline & & & & & Engineering, Mechanical & 29 & 81 \\
\hline & & & & & Engineering, Multidisciplinary & 24 & 53 \\
\hline & & & & & Engineering, Manufacturing & 16 & 2 \\
\hline \multirow[t]{8}{*}{3} & Linyi University & 611 & 810 & 1.32 & Engineering, Electrical \& Electronic & 216 & 175 \\
\hline & & & & & Engineering, Chemical & 33 & 93 \\
\hline & & & & & Engineering, Environmental & 38 & 176 \\
\hline & & & & & Engineering, Mechanical & 102 & 69 \\
\hline & & & & & Engineering, Multidisciplinary & 90 & 112 \\
\hline & & & & & Engineering, Industrial & 25 & 6 \\
\hline & & & & & Engineering, Manufacturing & 48 & 19 \\
\hline & & & & & Engineering, Civil & 39 & 23 \\
\hline \multirow[t]{8}{*}{4} & Weifang University & 641 & 655 & 1.02 & Engineering, Electrical \& Electronic & 169 & 122 \\
\hline & & & & & Engineering, Chemical & 58 & 229 \\
\hline & & & & & Engineering, Environmental & 39 & 39 \\
\hline & & & & & Engineering, Mechanical & 129 & 108 \\
\hline & & & & & Engineering, Multidisciplinary & 77 & 98 \\
\hline & & & & & Engineering, Industrial & 19 & 5 \\
\hline & & & & & Engineering, Manufacturing & 82 & 13 \\
\hline & & & & & Engineering, Civil & 43 & 12 \\
\hline \multirow[t]{6}{*}{5} & Zaozhuang & 195 & 307 & 1.57 & Engineering, Electrical \& Electronic & 58 & 84 \\
\hline & University & & & & Engineering, Chemical & 26 & 146 \\
\hline & & & & & Engineering, Environmental & 17 & 33 \\
\hline & & & & & Engineering, Mechanical & 28 & 10 \\
\hline & & & & & Engineering, Multidisciplinary & 37 & 25 \\
\hline & & & & & Engineering, Manufacturing & 15 & 6 \\
\hline \multirow[t]{4}{*}{6} & Dezhou University & 208 & 346 & 1.66 & Engineering, Electrical \& Electronic & 103 & 80 \\
\hline & & & & & Engineering, Chemical & 18 & 106 \\
\hline & & & & & Engineering, Mechanical & 27 & 38 \\
\hline & & & & & Engineering, Multidisciplinary & 23 & 24 \\
\hline \multirow[t]{3}{*}{7} & Jining University & 103 & 357 & 3.46 & Engineering, Electrical \& Electronic & 31 & 27 \\
\hline & & & & & Engineering, Chemical & 24 & 229 \\
\hline & & & & & Engineering, Mechanical & 20 & 63 \\
\hline \multirow[t]{2}{*}{8} & Heze University & 81 & 177 & 2.18 & Engineering, Electrical \& Electronic & 18 & 7 \\
\hline & & & & & Engineering, Chemical & 22 & 117 \\
\hline
\end{tabular}


in biochemistry and biochemistry, biochemistry and molecular biology, biodiversity conservation, biology, biophysics, biotechnology and applied microbiology. It can be seen from Table 4 that compared with other disciplines, the biology and biochemistry of 8 universities have less publications in 10 years. The largest number of papers is Dezhou University, with only 147 articles; The number of papers published by Linyi University was 124, and the number of papers published was the second; Jining University and Heze University have only 19 publications each in 10 years, with an average of less than 2 publications per year. Binzhou University has published 73 papers on biology and biochemistry, among which biotechnology and applied microbiology research has the highest volume, accounting for $36 \%$ of biology and biochemistry. The total number of citations was 1751, ranking first in eight universities, and the number of citations was 24.03/piece, therefore, the articles published by Binzhou University were cited more frequently than the ESI threshold. The largest number of publications in biochemistry and molecular biology is Dezhou University, with 70 articles. Binzhou University, which has the largest number of documents in biology, has only 17 papers. Linyi University has the largest number of documents in the direction of biotechnology and applied microbiology. The largest number of biophysical publications is Dezhou University.

As can be seen from Table 4, the research on biology and biochemistry in 8 universities is relatively weak. It can be inferred that the research in biology and biochemistry is relatively weak due to the limitations of experimental conditions and talent policies in the two universities. See Table 5.

Table 4. Comparative analysis of environment and ecology in 8 universities.

\begin{tabular}{|c|c|c|c|c|c|c|c|}
\hline Rank & Institutions & WOS Documents & Total Cites & Cites/Paper & WOS SUBJECT & papers $\geq 15$ & Cites \\
\hline \multirow[t]{2}{*}{1} & Binzhou University & 69 & 671 & 9.72 & Environmental Sciences & 68 & 671 \\
\hline & & & & & Environmental Studies & 1 & 0 \\
\hline \multirow[t]{2}{*}{2} & Linyi University & 150 & 503 & 3.35 & Environmental Sciences & 114 & 501 \\
\hline & & & & & Environmental Studies & 36 & 2 \\
\hline \multirow[t]{2}{*}{3} & Zaozhuang University & 33 & 272 & 8.24 & Environmental Sciences & 32 & 272 \\
\hline & & & & & Environmental Studies & 1 & 0 \\
\hline \multirow[t]{2}{*}{4} & Taishan University & 18 & 125 & 6.94 & Environmental Sciences & 12 & 117 \\
\hline & & & & & Environmental Studies & 6 & 8 \\
\hline 5 & Weifang University & 40 & 107 & 2.68 & Environmental Sciences & 40 & 107 \\
\hline \multirow[t]{2}{*}{6} & Dezhou University & 31 & 57 & 1.84 & Environmental Sciences & 29 & 57 \\
\hline & & & & & Environmental Studies & 2 & 0 \\
\hline \multirow[t]{2}{*}{7} & Heze University & 10 & 32 & 3.2 & Environmental Sciences & 9 & 32 \\
\hline & & & & & Environmental Studies & 1 & 0 \\
\hline 8 & Jining University & 5 & 12 & 2.4 & Environmental Sciences & 5 & 12 \\
\hline
\end{tabular}


Table 5. Comparative analysis of biology and biochemistry in 8 universities.

\begin{tabular}{|c|c|c|c|c|c|c|c|}
\hline Rank & Institutions & WOS Documents & Total Cites & Cites/Paper & WOS SUBJECT & papers $\geq 15$ & Cites \\
\hline \multirow[t]{3}{*}{1} & Binzhou University & 73 & 1754 & 24.03 & Biochemistry \& Molecular Biology & 18 & 521 \\
\hline & & & & & Biology & 17 & 750 \\
\hline & & & & & Biotechnology \& Applied Microbiology & 26 & 365 \\
\hline \multirow[t]{3}{*}{2} & Linyi University & 124 & 1378 & 11.11 & Biochemistry \& Molecular Biology & 35 & 265 \\
\hline & & & & & Biophysics & 26 & 406 \\
\hline & & & & & Biotechnology \& Applied Microbiology & 45 & 585 \\
\hline \multirow[t]{3}{*}{3} & Dezhou University & 147 & 1169 & 7.95 & Biochemical Research Methods & 15 & 148 \\
\hline & & & & & Biochemistry \& Molecular Biology & 70 & 562 \\
\hline & & & & & Biophysics & 30 & 178 \\
\hline \multirow[t]{2}{*}{4} & Taishan University & 56 & 433 & 7.73 & Biochemistry \& Molecular Biology & 17 & 86 \\
\hline & & & & & Biophysics & 15 & 49 \\
\hline \multirow[t]{2}{*}{5} & Zaozhuang University & 60 & 226 & 3.77 & Biochemistry \& Molecular Biology & 16 & 90 \\
\hline & & & & & Biology & 16 & 18 \\
\hline 6 & Weifang University & 32 & 178 & 5.56 & Biochemistry \& Molecular Biology & 17 & 126 \\
\hline
\end{tabular}

\subsection{Environmental and Ecological Discipline Analysis}

The core set of Web of science divides environment and ecology into two secondary disciplines: environmental science and environmental research. It can be seen from Table 6 that in terms of the number of papers, 150 papers from Linyi University rank first in terms of number of papers. The least amount of papers is Jining University, and the number of papers is only five. Binzhou University published 69 papers on environment and ecology, including 68 papers in environmental science, 671 times in total citations, and $1^{\text {st }}$ in 8 universities, the number of citations was 9.72 times/paper. More than 8 universities on environmental and ecological research focus on the direction of environmental science. There are very few papers in the direction of environmental research. For example, Binzhou University, Zaozhuang University, and Heze University each have only one related academic paper. There is no relevant paper in Jining University, and there are only 6 colleges with the largest number of publications. Linyi University has the largest number of documents in the environmental sciences, with a volume of 114 articles, followed by Binzhou University. According to various data, there are very few academic papers published by eight universities in environment and ecology.

All universities should strengthen management and investment in environmental and ecological aspects, and try to consider scientific research policies and talent introduction. The data are shown in Table 4.

\subsection{Physics Subject Analysis}

The core set of Web of science divides environment and ecology into eight secondary 
Table 6. Comparative analysis of physics in 8 universities.

\begin{tabular}{|c|c|c|c|c|c|c|c|}
\hline Rank & Institutions & WOS Documents & Total Cites & Cites/Paper & WOS SUBJECT & papers $\geq 15$ & Cites \\
\hline \multirow[t]{5}{*}{1} & Linyi University & 287 & 1950 & 6.79 & Physics, Applied & 91 & 651 \\
\hline & & & & & Physics, Atomic, Molecular \& Chemical & 34 & 221 \\
\hline & & & & & Physics, Condensed Matter & 59 & 355 \\
\hline & & & & & Physics, Mathematical & 36 & 206 \\
\hline & & & & & Physics, Multidisciplinary & 53 & 372 \\
\hline \multirow[t]{5}{*}{2} & Jining University & 260 & 1553 & 5.97 & Physics, Applied & 52 & 436 \\
\hline & & & & & Physics, Atomic, Molecular \& Chemical & 42 & 330 \\
\hline & & & & & Physics, Condensed Matter & 49 & 373 \\
\hline & & & & & Physics, Mathematical & 16 & 21 \\
\hline & & & & & Physics, Multidisciplinary & 74 & 340 \\
\hline \multirow[t]{4}{*}{3} & Dezhou University & 140 & 1400 & 10 & Physics, Applied & 50 & 520 \\
\hline & & & & & Physics, Atomic, Molecular \& Chemical & 15 & 87 \\
\hline & & & & & Physics, Condensed Matter & 28 & 398 \\
\hline & & & & & Physics, Multidisciplinary & 27 & 201 \\
\hline \multirow[t]{4}{*}{4} & Taishan University & 143 & 845 & 5.91 & Physics, Applied & 61 & 332 \\
\hline & & & & & Physics, Atomic, Molecular \& Chemical & 21 & 178 \\
\hline & & & & & Physics, Condensed Matter & 27 & 175 \\
\hline & & & & & Physics, Multidisciplinary & 24 & 113 \\
\hline \multirow[t]{4}{*}{5} & Binzhou University & 132 & 650 & 4.92 & Physics, Applied & 27 & 71 \\
\hline & & & & & Physics, Atomic, Molecular \& Chemical & 23 & 152 \\
\hline & & & & & Physics, Condensed Matter & 20 & 102 \\
\hline & & & & & Physics, Multidisciplinary & 40 & 206 \\
\hline \multirow[t]{4}{*}{6} & Heze University & 162 & 605 & 3.73 & Physics, Applied & 22 & 102 \\
\hline & & & & & Physics, Condensed Matter & 20 & 43 \\
\hline & & & & & Physics, Mathematical & 16 & 17 \\
\hline & & & & & Physics, Multidisciplinary & 91 & 411 \\
\hline \multirow[t]{2}{*}{7} & Weifang University & 87 & 282 & 3.24 & Physics, Applied & 38 & 119 \\
\hline & & & & & Physics, Multidisciplinary & 28 & 59 \\
\hline \multirow[t]{2}{*}{8} & Zaozhuang University & 82 & 192 & 2.34 & Physics, Applied & 26 & 67 \\
\hline & & & & & Physics, Multidisciplinary & 23 & 38 \\
\hline
\end{tabular}

disciplines: applied physics, atomic physics, polymer physics, mathematical physics, and nuclear physics. From the number of papers, Linyi University has the largest number of papers, totaling 287 papers; The least amount of papers was Zaozhuang University, and the number of papers was only 82 . From the citation frequency, Linyi University's total citation frequency is the highest total citation frequency of 1950 times; Zaozhuang University has the lowest frequency 
of citations, mainly because its number of posts is too small. The highest number of citations was from Dezhou University, 10 times/piece, and the last institution ranked $1 \%$ before ESI was the University of Kentucky. The citations were 17.87 times/paper, so the general undergraduate in Shandong Province, there is still a big gap between colleges and world-class disciplines. In the fields of applied physics, polymer physics, and mathematical physics, Linyi University has the largest number of publications, which shows that it is higher than the other seven universities in these three directions. The largest number of documents in the interdisciplinary direction of atomic physics and physics is Jining University, with only 42 articles.

It can be seen from the above data that the gap between the physics research of the eight universities and the world-class universities is very large, mainly due to the talent problem. Among the more than 8 colleges and universities, the most prominent physics research is Linyi University and Jining University. See Table 6 for details.

\subsection{Computer Science Subject Analysis}

Web of science divides computer science into eight secondary disciplines for computer science: Artificial Intelligence, Cybernetics, Hardware \& Architecture, Information Systems, Interdisciplinary Applications, Theory \& Methods, Software Engineering. When counting the two secondary disciplines, only the disciplines with a volume of $\geq 15$ articles were counted, and the second-level disciplines with less than 15 articles were ignored here.

In terms of the number of papers, 573 Weifang University ranked first, and 561 papers from Linyi University ranked second; Heze University has the least amount of papers, only 52 articles. In terms of total times cited, the highest is Taishan University, 620 times; Secondly, Linyi University, the total number of citations was 580 times; Among the 8 colleges and universities, the highest number of papers cited was Binzhou University, 5.01 times/paper. The most published in the direction of Artificial Intelligence is Weifang University, 127 articles; Linyi University has the largest number of documents in Information Systems and Theory \& Methods; Weifang University is in the direction of computer science, with more research on Interdisciplinary Applications. The number of papers in each direction of Binzhou University, Dezhou University, Zaozhuang University, Heze University, Jining University, Taishan University no more than 100 papers. In particular, Heze University and Jining University have only one research direction with more than 15 articles. Therefore, these six colleges have a certain gap in computer science compared to Weifang University and Linyi University. See Table 7.

\section{Conclusions}

The data is the most iconic performance of anything. From the above data, we can see that there are very wide gaps in the number of universities in the eight 
Table 7. Comparative analysis of computer science in 8 universities.

\begin{tabular}{|c|c|c|c|c|c|c|c|}
\hline Rank & Institutions & WOS Documents & Total Cites & Cites/Paper & WOS SUBJECT & papers $\geq 15$ & Cites \\
\hline \multirow[t]{3}{*}{1} & Taishan University & 169 & 620 & 3.67 & Artificial Intelligence & 42 & 350 \\
\hline & & & & & Information Systems & 28 & 15 \\
\hline & & & & & Interdisciplinary Applications & 33 & 124 \\
\hline \multirow[t]{6}{*}{2} & Linyi University & 561 & 580 & 1.03 & Artificial Intelligence & 101 & 283 \\
\hline & & & & & Hardware \& Architecture & 18 & 14 \\
\hline & & & & & Information Systems & 122 & 72 \\
\hline & & & & & Interdisciplinary Applications & 144 & 95 \\
\hline & & & & & Software Engineering & 17 & 39 \\
\hline & & & & & Theory \& Methods & 145 & 64 \\
\hline \multirow[t]{6}{*}{3} & Weifang University & 573 & 420 & 0.73 & Artificial Intelligence & 127 & 92 \\
\hline & & & & & Hardware \& Architecture & 19 & 11 \\
\hline & & & & & Information Systems & 117 & 103 \\
\hline & & & & & Interdisciplinary Applications & 148 & 87 \\
\hline & & & & & Software Engineering & 22 & 47 \\
\hline & & & & & Theory \& Methods & 138 & 80 \\
\hline \multirow[t]{3}{*}{4} & Binzhou University & 74 & 371 & 5.01 & Artificial Intelligence & 22 & 146 \\
\hline & & & & & Interdisciplinary Applications & 15 & 82 \\
\hline & & & & & Theory \& Methods & 16 & 2 \\
\hline \multirow[t]{5}{*}{5} & Dezhou University & 269 & 320 & 1.19 & Artificial Intelligence & 42 & 69 \\
\hline & & & & & Hardware \& Architecture & 16 & 17 \\
\hline & & & & & Information Systems & 54 & 51 \\
\hline & & & & & Interdisciplinary Applications & 82 & 134 \\
\hline & & & & & Theory \& Methods & 62 & 34 \\
\hline \multirow[t]{4}{*}{6} & Zaozhuang University & 161 & 132 & 0.82 & Artificial Intelligence & 41 & 34 \\
\hline & & & & & Information Systems & 30 & 48 \\
\hline & & & & & Interdisciplinary Applications & 41 & 40 \\
\hline & & & & & Theory \& Methods & 38 & 7 \\
\hline 7 & Heze University & 52 & 30 & 0.58 & Artificial Intelligence & 18 & 9 \\
\hline 8 & Jining University & 56 & 26 & 0.46 & Artificial Intelligence & 15 & 5 \\
\hline
\end{tabular}

universities. The horizontal comparison of the eight universities, the volume of publications and the depth of research in each discipline are not the same. Comprehensively, Linyi University has obvious academic advantages in 8 universities, but the comprehensive data of Zaozhuang University and Heze University are relatively low.

It can also be seen from the data that due to the limitations of experimental conditions, talent policies, scientific research awards, etc., the research in some 
experimental and technical disciplines is relatively weak, such as biology students' chemistry and environment, science and so on. In addition, in ordinary colleges and universities, the main research force is generally young doctors and graduate students, but this part of the teachers has heavy work tasks and more teaching time, so that the research time is less [5]. The management of ordinary colleges and universities can adjust internal talent management policies and research incentive policies according to the gap between disciplines. At the same time, it is hoped that China's relevant scientific research and education management departments will take corresponding measures to encourage university faculty and students to carry out scientific research and innovation, and accelerate the output of scientific research results.

This paper only studies the status quo of scientific research in universities from the perspective of thesis, and there is a certain one-sidedness. The author will further study from scientific research cooperation, patent cooperation and cooperation in science and technology projects.

\section{Conflicts of Interest}

The author declares no conflicts of interest regarding the publication of this paper.

\section{References}

[1] Zhao, R.Y., Wang, X. and Qi, Y.K. (2019) Study on Scientific Collaboration Network and Evolution of Construction of World-Class Universities in China. Journal of Modern Information, 39, 132-143.

[2] Hua, B.L. (2016) Types and Description Rules of Knowledge Elements about Method in Academic Papers. Journal of Library Science in China, 42, 30-40.

[3] Hou, Z.J. (2018) Research on Method of Predicting the Time of Entering ESI Top $1 \%$ for College Disciplines Based on InCites. Library Work and Study, No. 4, 37-45.

[4] Cheng, J.-P., Liu, J.-H. and Ye, M. (2018) A Modified Model for Potential Disciplines Forecast and Empirical Analysis Based on ESI. Information Science, 36, 22-24+40.

[5] Lu, L. and Yu, W. (2015) Struggling and Breakthrough in the Research of Young Teachers in Colleges and Universities. Chinese University Science \& Technology, No. 12, 11-13. 